\title{
FATORES QUE INFLUENCIAM IDOSOS DE UM MUNICÍPIO DO SUL DE SANTA CATARINA A ADQUIRIR UM DETERMINADO MEDICAMENTO ISENTO DE PRESCRIÇÃO MÉDICA (MIP)
}

FACTORS THAT INFLUENCES ELDERLY OF A SOUTH SANTA CATARINA'S CITY TO ACQUIRE A DETERMINED OVER-THE-COUNTER (OTC) DRUG

Dyeison Bernardo Matias'; Eduardo João Agnes²

${ }^{1}$ Aluno da Pós-Graduação Unesc.

${ }^{2}$ Farmacêutico/Bioquimico, Docente Pós Graduação Unesc.

\section{Endereço para correspondência}

Departamento de Pós Graduação Lato Sensu

Universidade do Extremo Sul Catarinense - UNESC 88950-000, Jacinto Machado, Santa Catarina, Brasil

E-mail: dyeiison@unesc.net

Departamento de Farmácia

Universidade do Extremo Sul Catarinense - UNESC

E-mail: eja@unesc.net 


\section{RESUMO}

Durante anos vamos observando a evolução da propaganda e da utilização da mídia de massa para promoção de medicamentos caracterizados como MIPs (medicamentos isentos de prescrição) que são aqueles com venda livre nos balcões das farmácias, pois não necessitam de receita médica. Escolhas, em geral, são frutos de influências e a influência é um dos fenômenos habitualmente ocorridos no relacionamento interpessoal e pode induzir o indivíduo a um determinado comportamento. Sendo assim, este estudo teve como objetivo principal avaliar e entender quais são essas influências que levam o público idoso á compra de determinado MIP, avaliando de forma descritiva e exploratória, com questões estruturadas e objetivas, a frequência de utilização de MIPs, as características que levam a compra, os influenciados interpessoais, meios de comunicação e sua influência com a propaganda. Podemos destacar a influência que as propagandas de televisão tem na aquisição e consequentemente na automedicação, e as características que determinam a finalização da compra são principalmente o preço, seguido da marca conhecida. Se tratando de um grupo específico, os idosos procuram a maneira mais simples de administrar o medicamento, sendo assim, também optam pelo modo de administração mais cômodo a eles. Portanto, este estudo traz dados relevantes à indústria farmacêutica, pois os idosos são hoje os que mais consomem remédios, por isso conhecer suas preferências, os motivos que os levam às farmácias e quais meios possuem maior poder em sua decisão de compra mostram os caminhos que o marketing pode percorrer para chegar a seu público alvo.

Descritores: MIPs, medicamentos, idosos, influência.

\section{ABSTRACT}

For years we are watching the evolution of advertising and the use of mass media to promote OTC (over-the-counter) drugs that are medicines sold directly to a consumer without prescription from a medical doctor. Choices, in general, are provided by influences and the influence is one of the phenomena that occur usually in interpersonal relationships and can induce the person to a determined behavior. By 
the way, this study aimed to evaluate and understand which are these influences that lead the elderly public to buy a determined OTC drug, evaluating descriptive and exploratory way, with structured and objective questions, the frequency of use of OTC drugs, the features that lead to buy, interpersonal influenced, media and its influence with advertising. We can point out the influence that television advertising has in the acquisition and consequently self-medication, and the characteristics that determine the checkout are mostly the price, followed by the well-known brands. As a specific group, the elderly seek the simplest way to administer the drug, and thus also opt for more convenient administration to them. Therefore, this study presents relevant data to the pharmaceutical industry, because today elderly are those who consume more drugs, so, know your preferences, the reasons that lead them to the pharmacies and which ways have greater influence in their buying decision show us the ways that the marketing can go to reach your target audience.

Descriptores: OTC drugs, elderly, influence. 


\section{INTRODUÇÃO}

O comércio do ramo farmacêutico é claramente um dos mais competitivos, complexos, lucrativos e inovadores desta época. Neste ramo atuam gigantes indústrias globais, que chegam a investir bilhões de reais na pesquisa, desenvolvimento e comercialização de seus produtos ${ }^{1}$. Conforme Rossi (2001), o mercado farmacêutico compõe um segmento ascendente, com expectativa de 8,1\% ao ano, sendo caracterizado como um comércio monopolizado e/ou oligopolizado, sendo as empresas líderes sediadas em grandes polos industriais nos Estados Unidos e Europa, com suas subsidiárias presentes em diversos países.

No Brasil, as indústrias farmacêuticas predominam no mercado há muito tempo. Entretanto, nos últimos 20 anos houve algumas modificações significativas, como a implantação das leis de Patentes e dos Genéricos, onde o mercado nacional iniciou um processo de transformação e se mostrou em outro ângulo: ao lado dos conglomerados transnacionais se avança e desponta uma indústria potente e competidora ${ }^{2}$.

Observa-se também, em âmbito nacional, a ampliação dos investimentos destes laboratórios farmacêuticos, à medida que aumenta o poder aquisitivo dos consumidores. Com a alta demanda de abertura de laboratórios farmacêuticos observa-se o aumento da carga empregatícia, especialmente na área de marketing farmacêutico, e para os propagandistas vendedores de medicamentos, que são os profissionais responsáveis pela geração da demanda de medicamentos, através das visitas que fazem aos médicos ${ }^{4}$.

Em anos, vamos observando a sistemática evolução da propaganda e da utilização da mídia de massa para promoção de medicamentos caracterizados como OTC (Over The Counter), que são aqueles com venda livre nos balcões das farmácias, pois não necessitam de receita médica. Esses produtos também são amplamente conhecidos como MIP (Isentos de Prescrição Médica) e detém pouco esforço do propagandista para venda, já que muitas vezes sua promoção é realizada através de anúncios em revistas ou jornais, assim como em comerciais de TV ou rádio. Desde o início do século passado essa promoção era realizada com grande ostentação e o papel do propagandista, nesta época, era bastante restritivo, focado apenas em outra classe de medicamentos ${ }^{5}$. 
Conforme Pereira et al. (2000), se antes o propagandista tinha como objetivo levar informações ao médico e tentar persuadi-lo a prescrever seus produtos baseados apenas nas características, vantagens e benefícios, hoje ele tem um segundo público a influenciar através da figura do médico: o paciente.

Escolhas, em geral, são frutos de influências, podendo ser conscientes ou inconscientes, intencionais ou não. A influência é um dos fenômenos habitualmente ocorridos no relacionamento interpessoal e pode induzir o indivíduo a um determinado comportamento. Conforme Rodrigues et al. (1999), um enorme investimento financeiro em propaganda evidencia a confiança na probabilidade de as pessoas serem influenciadas.

Sendo assim, este estudo tem por objetivo principal avaliar e entender quais são essas influências que levam o público idoso á compra de determinado medicamento isento de prescrição médica (MIP).

\section{MÉTODOS}

Para obter os resultados deste trabalho foi realizado a coleta de dados de forma descritiva e exploratória, portanto, trata-se de um tema pouco explorado e uma pesquisa cujo tema é o comportamento do consumidor com relação aos medicamentos isentos de prescrição médica (MIP) em uma amostra definida por conveniência.

O levantamento e análise de dados coletados na pesquisa foi realizado por um questionário previamente estruturado, com questões fechadas e de multiplaescolha, sendo que os entrevistados responderam as questões com o objetivo de elucidar as informações nas quais eram importantes aos objetivos do trabalho. A abordagem se consistiu focalizada no problema, sendo quali quantitativa, utilizando-se de medidas estatísticas para análise dos dados coletados.

O questionário foi elaborado baseando-se na identificação do comportamento do consumidor idoso, que adquire medicamento isento de prescrição médica dentro desta amostra. A coleta de dados foi efetuada no período entre 10 de setembro de 2015 até 15 de outubro de 2015, sendo realizadas simultaneamente no centro de convivência da terceira idade e Hospital São Roque, 
amos da cidade de Jacinto Machado/SC. Inicialmente, foi aplicado para uma pequena amostra circulante do Hospital São Roque, afim de corrigir possíveis falhas e dificuldades metodológicas, ocorridas na confecção do questionário. Posteriormente, foi aplicado ao restante da amostra já citada anteriormente no trabalho. A técnica utilizada foi a de amostragem não probabilística aleatória.

\section{RESULTADOS}

Foram abordados e entrevistados, aleatoriamente, 50 idosos. Dentre eles, 48 responderam adquirir medicamentos sem prescrição medica (MIP), estando qualificados para participar da pesquisa.

A frequência na qual os idosos fazem a aquisição desses medicamentos é, de sua grande maioria, uma vez ao mês, como mostra a figura abaixo.

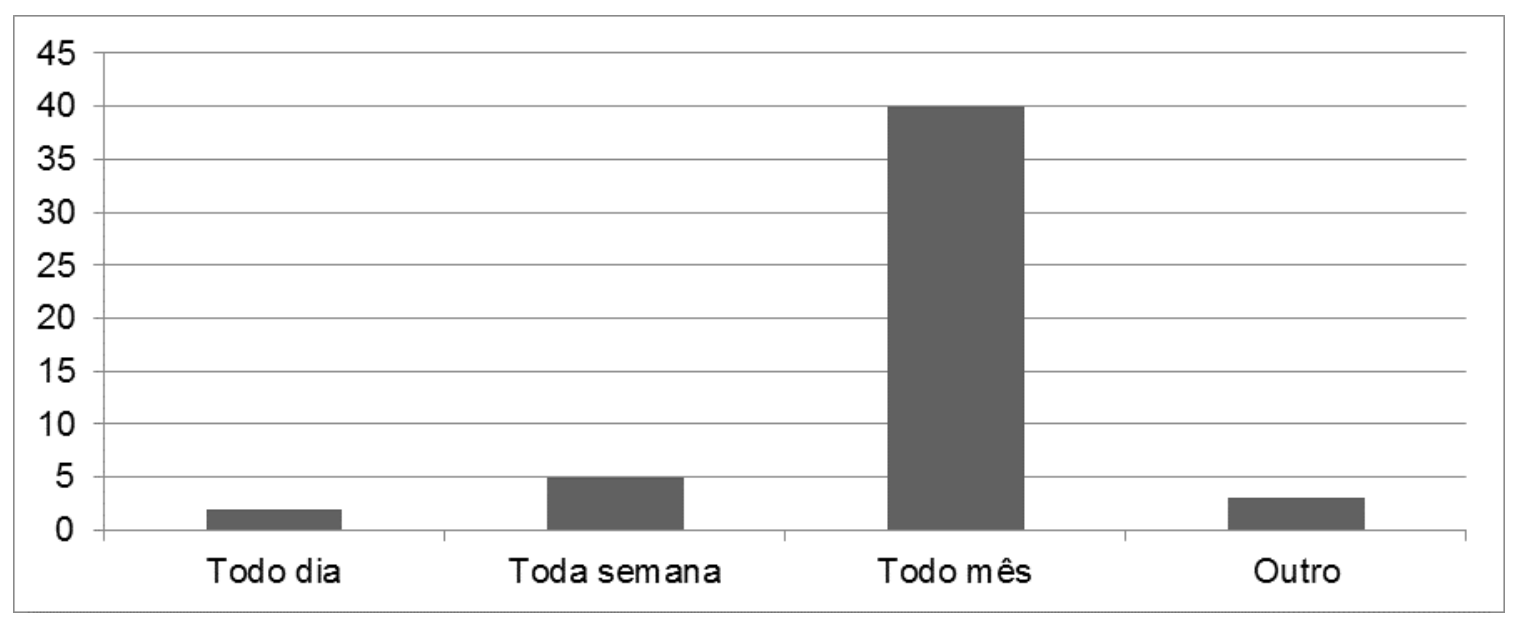

FIGURA 1 - Frequência de aquisição de MIPs.

Em meio aos entrevistados, 48 afirmaram ter o hábito de comprar medicamentos isentos de prescrição médica, sendo observada durante o roteiro de entrevista a naturalidade deste hábito no cotidiano dos entrevistados, fazendo parte fundamental nas compras mensais de uso individual ou familiar, sendo responsável por grande parcela do orçamento mensal. É indispensável salientar que a frequência de compra não tem, necessariamente, relação com a quantidade de medicamentos adquiridos no momento da compra, uma vez que a prática de estocagem de 
medicamentos em casa é muito comum entre os entrevistados (FIGURA 4).

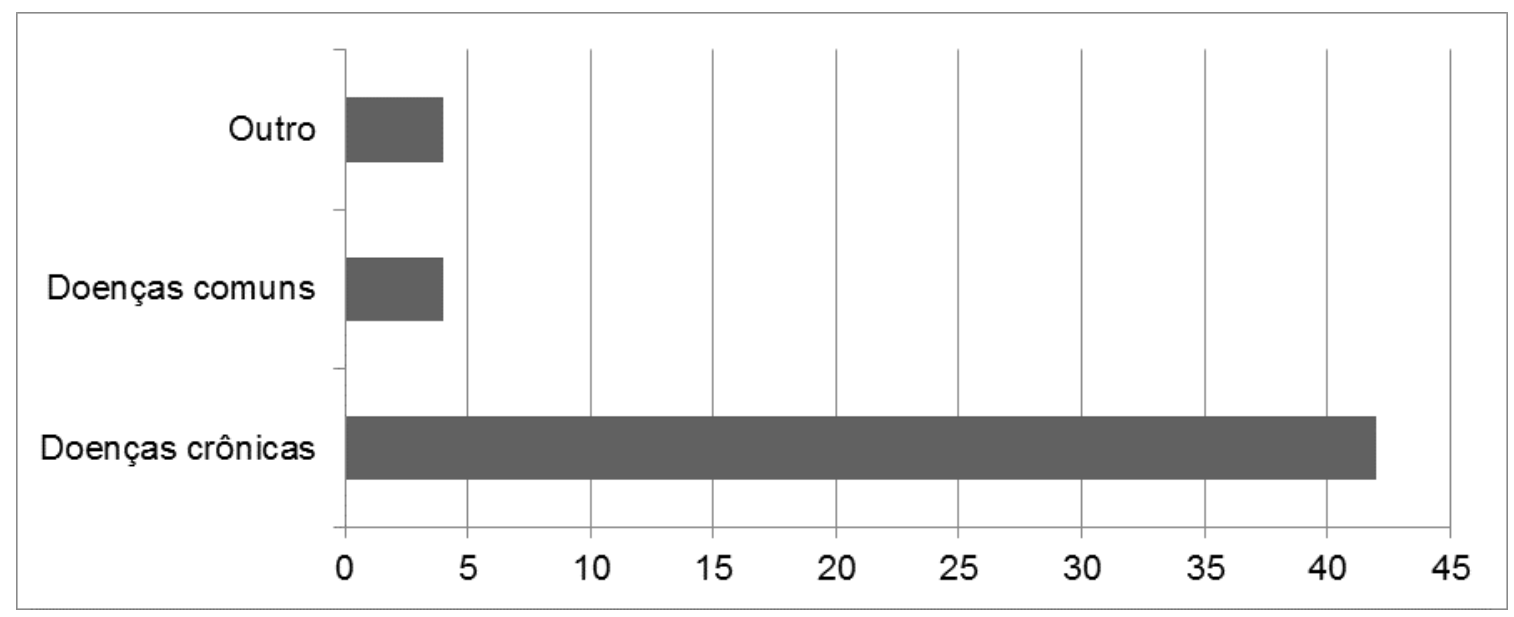

FIGURA 2 - Motivos dos entrevistados para a aquisição de MIPs.

Nesta questão, durante a coleta de dados, foram citados pelo entrevistado diversos nomes e marcas de medicamentos, podendo ser observados nomes comerciais e princípio ativo, sendo eles, no momento da compilação dos dados, separados em medicamentos para tratar doenças crônicas (hipertensão arterial, dislipidemias, doenças cardíacas), doenças comuns (gripe, resfriado, dores) e outros (inflamações agudas, antiulcerosos, etc).

Dentre os medicamentos citados estão: maleato de enalapril, losartana potássica, hidroclorotiazida, Eno®, Cimegripe $\AA$, Centrum $\AA$, vitamina $C$, omeprazol, etc. Durante a entrevista pôde-se compreender que o consumidor idoso conhece melhor a marca do medicamento que o próprio principio ativo, quando não se trata de doenças crônicas. Este ponto foi muito observado também na próxima questão da entrevista, onde o idoso foi perguntado quais os MIPs que eram adquiridos (FIGURA 3). 


\section{Gestão em Saúde}

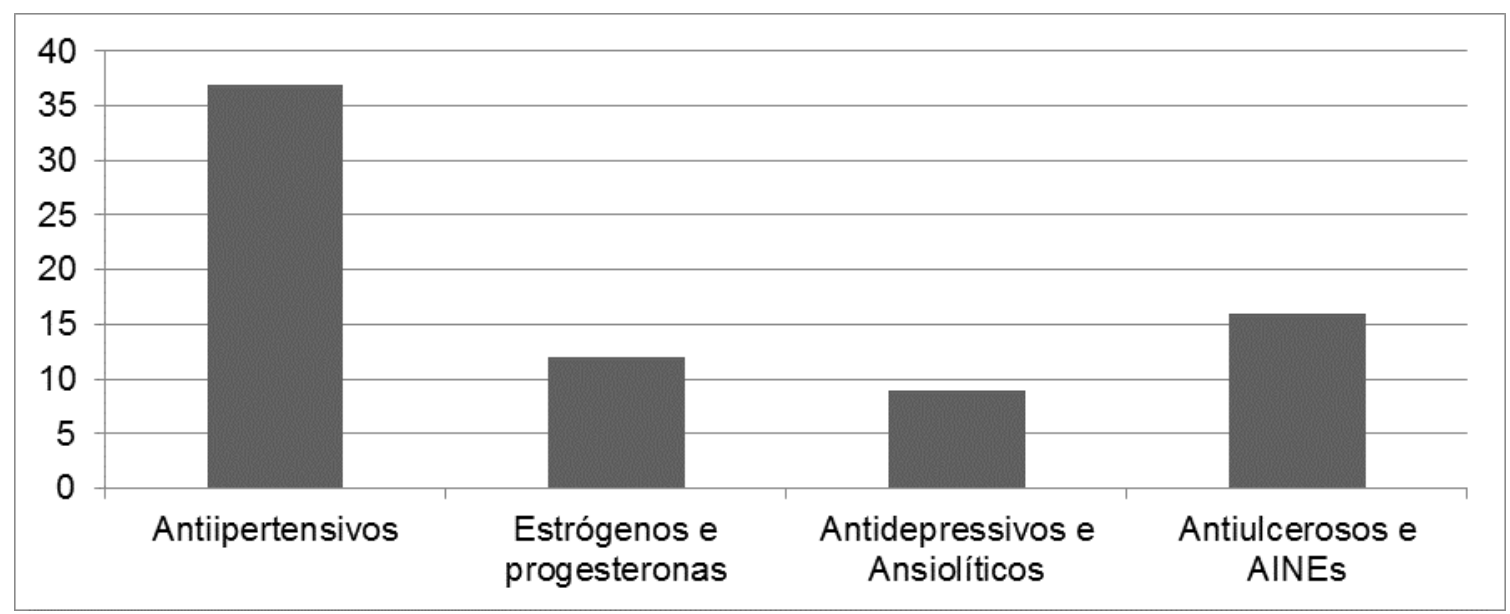

FIGURA 3 - Classes de MIP's mais adiquiridos dos entrevistados.

Neste momento, a questão foi de multiplaescolha, sendo que os entrevistados poderiam escolher uma ou mais opções. Foram identificadas 12 classes terapêuticas dentre os medicamentos citados, sendo as mais comuns: antiipertensivos, tratamentos hormonais com estrógeno e progesterona, antiulcerosos, antiinflamatórios não esteroidais (AINEs) e, antidepressivos e ansiolíticos de venda livre - sendo citados muitos medicamentos fitoterápicos com promessa ansiolítica e antidepressiva (FIGURA 3).

Quando perguntado quais características do medicamento que o entrevistado leva em conta no momento da decisão de compra de um MIP, a maioria respondeu que o preço influencia muito, seguido pela marca e pelo modo de administração que seja mais cômodo (FIGURA 4). Nesta questão fica evidenciado que o preço é o fator que mais influencia na decisão de compra (44 entrevistados), sendo refletido no que o autor Solomon (2002) fala sobre a fidelização e identificação do consumidor com a marca. Quando tratado do produto já conhecido o que menos importa para o consumidor é o design da embalagem (menos de 5\%). 0 fator preço, destacado pela maioria como mais importante na aquisição, evidencia que os MIPs, que não necessitam a visita de um médico, o custo acaba sendo fator importante, em em essência, a sua facilidade de uso. 


\section{Gestão em Saúde}

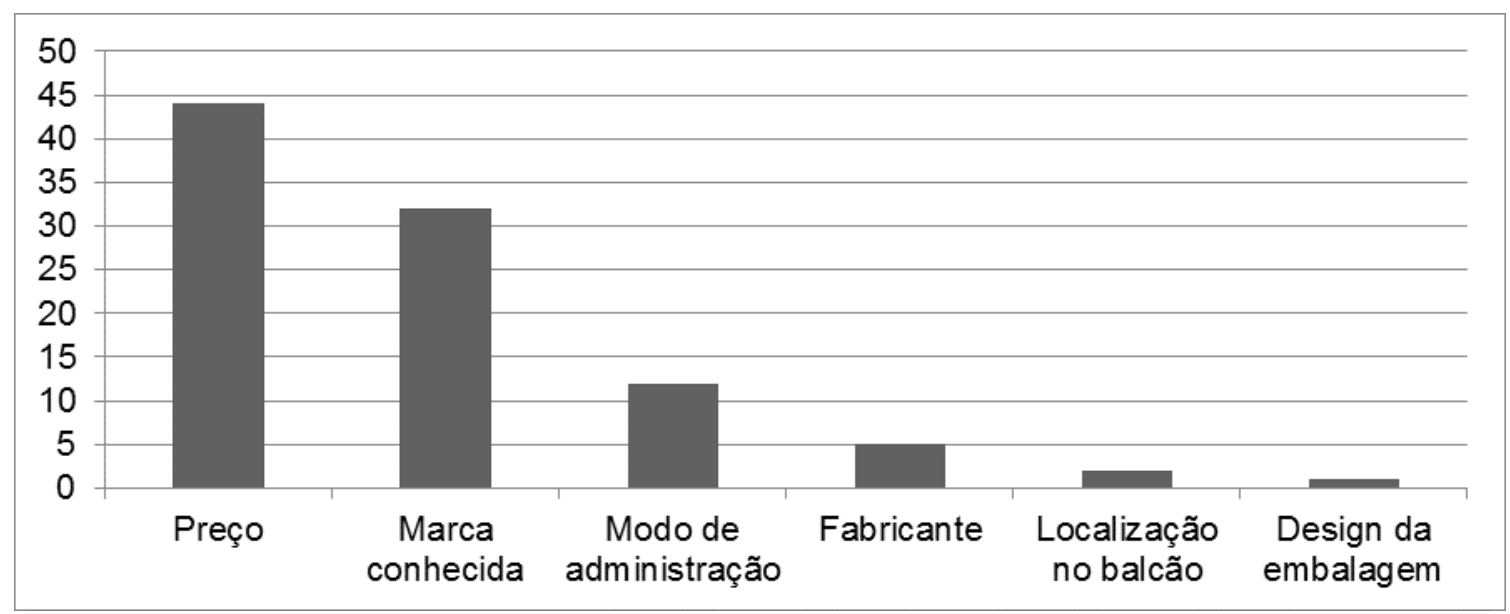

FIGURA 4 - Características da decisão de compra de um MIP pelo entrevistado.

Podemos perceber também, que a localização do medicamento no balcão da farmácia, tanto quanto o design da embalagem não influencia muito na compra deste publico alvo (FIGURA 4).

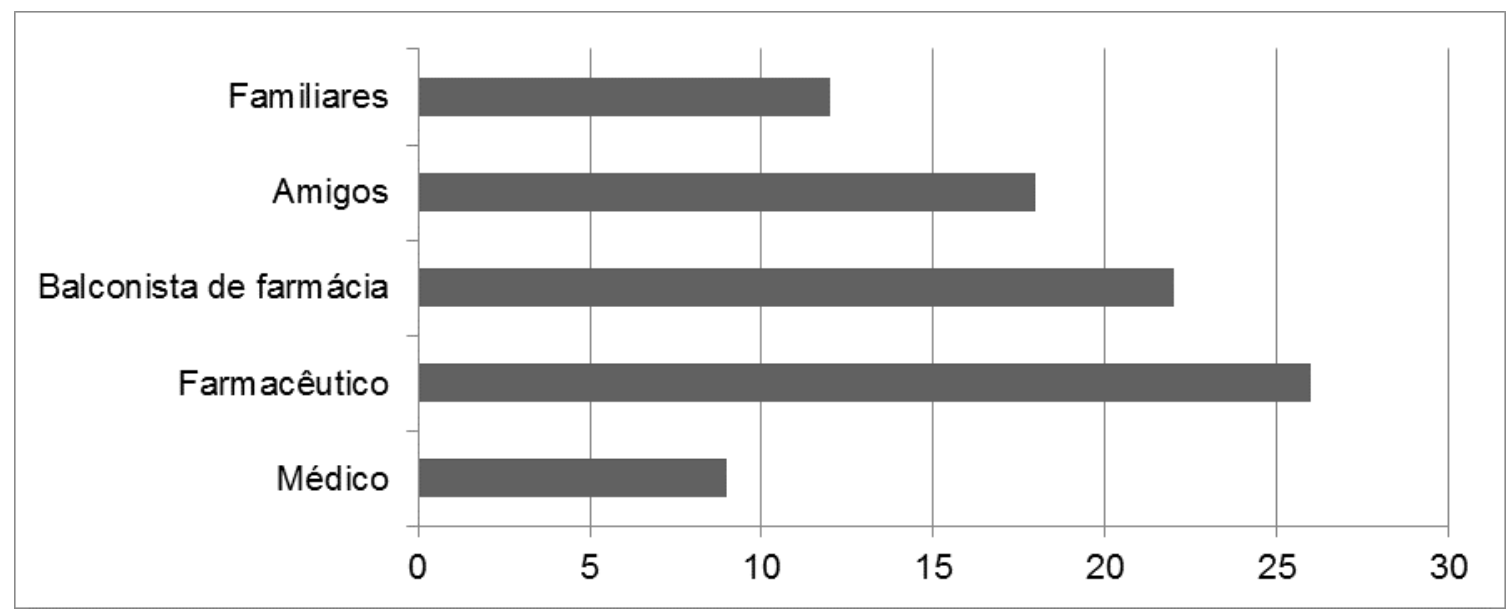

FIGURA 5 - Influenciadores da compra de um MIP segundo o entrevistado.

Ao ser perguntado se consultou alguém ao fazer a compra de um determinado MIP, notasse que o profissional mais solicitado a indicar um MIP é o farmacêutico, sendo que o profissional médico encontra-se em último caso a ser procurado pelo entrevistado (FIGURA 5). 
No momento que o entrevistado foi perguntado se faz a aquisição de MIPs através de propagandas, sendo citado a televisão, a internet, o rádio e materiais impressos, tivemos resposta positiva de 34 dos entrevistados. Destes 34 , foi indagado a ele por qual meio de propaganda ele conheceu o produto e resolveu adiquiri-lo, onde grande maioria (28) conheceu pela televisão (FIGURA 6).

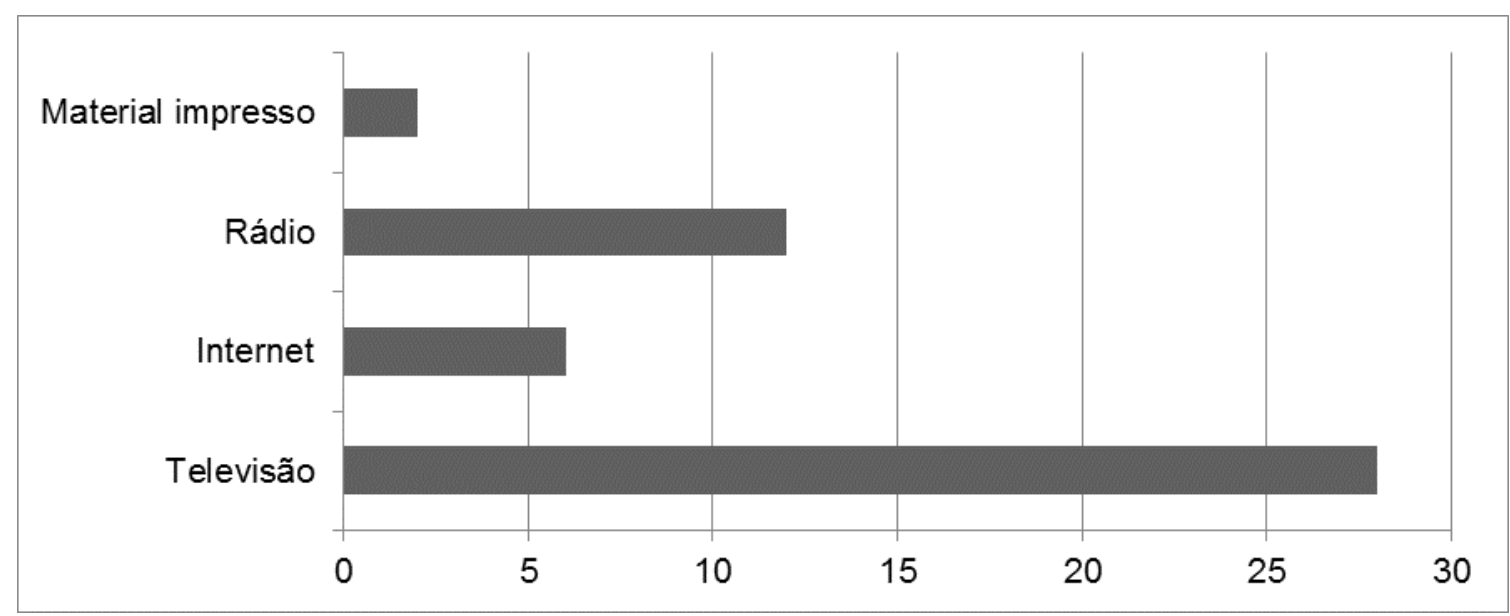

FIGURA 6 - Meio de comunicação responsável pela compra de um MIP segundo o entrevistado.

A compra desnecessária desses medicamentos pelo entrevistado, influenciado pela propaganda nos meios de comunicação como podemos observar (FIGURA 6), leva ao habito de estocagem de medicamentos em seu domicilio e uma possível pratica de automedicação (FIGURA 7). 


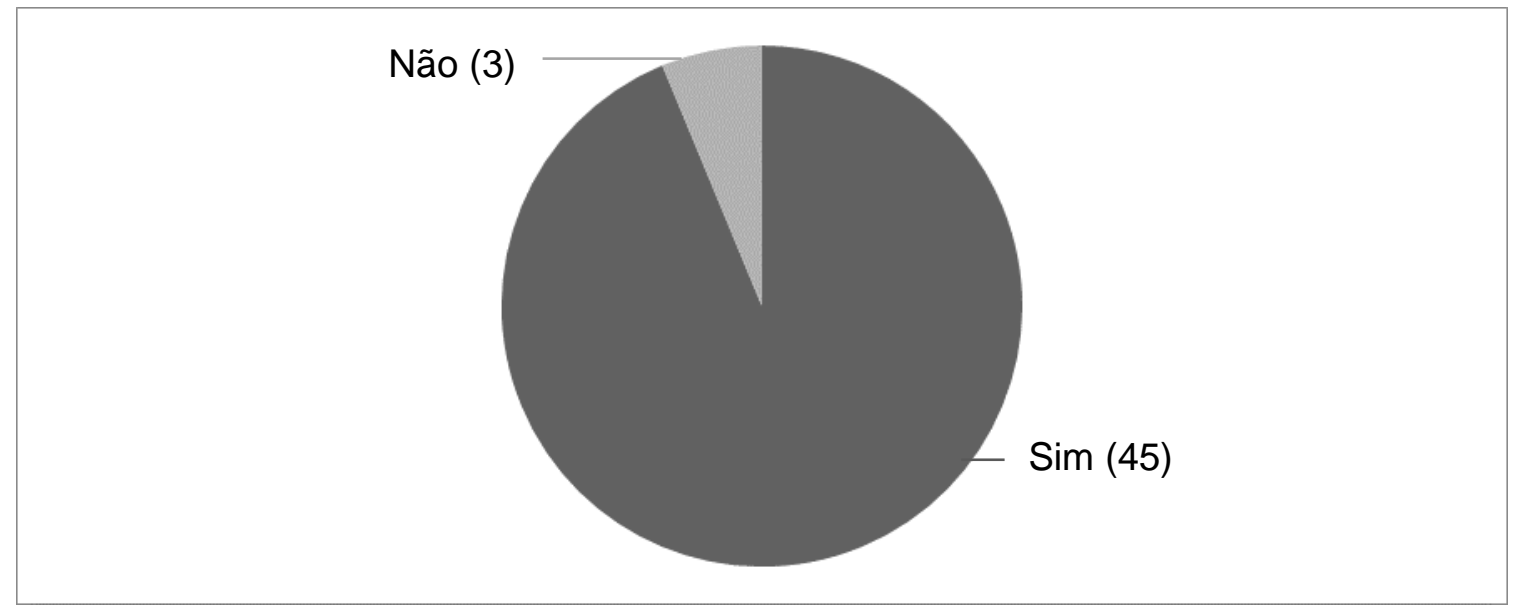

FIGURA 7 - Prática de estocagem de medicamentos segundo o entrevistado.

Quando perguntados se praticam a estocagem de MIPs em casa, 3 entrevistados afirmaram que não possuem MIPs guardados em sua residência, sendo sua maioria, 45, afirmando que estocam, comentando que acreditam nos riscos da automedicação mas seguem a pratica e assumem os riscos por estarem familiarizados com determinados medicamentos ou pela questão de alguma emergência cotidiana.

\section{DISCUSSÃO}

Segundo Solomon (2016), o consumidor idoso de hoje em dia é caracterizado da seguinte maneira: genericamente definido como ativo, interessado no que a vida tem a lhe oferecer e um consumidor entusiasmado, com os meios e a disposição para comprar muitos produtos e serviços; quer levar uma vida ativa e ser auto-suficiente; possui casa própria (em sua grande maioria); valoriza os elos que tem com os amigos e com a família; é altruísta e quer dar algo em troca para o mundo; sente-se mais jovem do que é cronologicamente (apesar das enfermidades); sente-se mais inclinado a gastar dinheiro consigo próprio do que com filhos e netos; é cético quanto a promoções vagas ou relacionadas apenas à imagem; tem mais 
dificuldade em ler e abrir embalagens e reage positivamente a anúncios com abundância de informações.

Para que uma segmentação de mercado seja levada a cabo pelas empresas brasileiras, vários motivos podem ser relacionados ao mercado da terceira idade: diferenças de poder aquisitivo, diferenças de hábitos e valores regionais, o surgimento de novos nichos dentro do segmento ou a existência de outros ainda mal atendidos. Entretanto, para que seja efetiva, a segmentação deve estar baseada em informação útil sobre o mercado. Devemos alinhar a influência dos profissionais de saúde, familiares, meio social, com a propaganda bem desenvolvida por estas empresas $^{8}$.

Neste estudo, quando perguntado sobre a frequência de aquisição de MIPs, percebemos que a aquisição dos medicamentos acontece, em sua maioria, mensalmente. É preciso considerar, o que Kiyotani (2014) chama de comportamento pós compra, em que ocorre a satisfação pós compra (expectativas atendidas e resultado alcançado) e ações pós-compra (se o consumidor estiver satisfeito, a tendência é que ele compre novamente o medicamento).

Para Custódio e Vargas (2005), o balconista, interessado em ganhar a comissão pela venda, estimula o idoso a realizar nova compra. De acordo com o perfil dos entrevistados, isso ocorre mensalmente, pois é o período que leva para o idoso realizar nova visita à farmácia. Isso ocorre devido ao perfil dos entrevistados, muitos residem no interior e vem ao centro uma vez por mês, onde realizam suas compras mensais. A compra de medicamentos para este público está entre os itens fundamentais, que compram no inicio do mês, quando recebem sua aposentadoria, assim como pagar despesas de luz, água, ir ao mercado, incluem ida a farmácia. É válido destacar que muitos compram a prazo, e ao retornarem a farmácia no inicio do mês para pagar, acabam realizando novas compras. Ao retornarem à farmácia, os funcionários, como apontam Custódio e Vargas (2005), na ausência de farmacêutico e contrariando a determinação da lei, praticam a chamada "empurroterapia", estimulada por laboratórios que pagam comissões ou dão prêmios aos proprietários para incentivar a maior comercialização de seus produtos. Criando um ciclo mensal de compras. 
Kotler, Kartajaya e Setiawan (2010, p. 34) citam que "os consumidores acreditam mais uns nos outros do que nas empresas [...] Os consumidores voltamse para o boca a boca como uma maneira nova e confiável de propaganda". O autor argumenta que por culpa das próprias marcas e a forma como usam o marketing, algumas vezes é visto como sinônimo de persuasão e manipulação, o que faz com que confiem nas recomendações de conhecidos. A fidelização do consumidor com a marca e a decisão de compra é altamente influenciada pela opinião e comportamento do grupo que a pessoa esteja inserida, as recomendações para usar ou evitar determinado medicamento acontece em conversas do dia a dia.

Os relacionamentos entre pessoas e grupos são um dos principais fatores para influencia na tomada de decisões, isso também inclui decisão de compra diante da necessidade de consumo. "Os grupos de referência de uma pessoa são aqueles que exercem alguma influência direta ou indireta sobre as atitudes ou o comportamento dessa pessoa.", Kotler e Keller (2006, p.177). Segundo Solomom (2002) os elos entre as pessoas de um grupo são fortalecidos pelos produtos em comum que eles utilizam, pois a partir desses conversam e trocam informações.

O sintoma patológico leva pessoas a pedirem ajuda aos profissionais de saúde e recorrerem ao medicamento em busca de alívio ao sofrimento. Muitas vezes isso não ocorre em consultório médico, mas, por exemplo, em um balcão de farmácia, conforme retratado no estudo. Neste estudo, mais de $70 \%$ dos idosos sofrem influência na compra de algum MIPs, sendo que os profissionais de saúde, familiares e amigos tem importante papel neste hábito.

Segundo Souza, Mesquita e Lara (2013), o médico ocupa o papel de intermediador entre a indústria farmacêutica e o consumidor, mesmo quando se trata de medicamentos livres de receita médica. Mas percebe-se a influência de outro profissional envolvido, o farmacêutico ou o balconista, que agem como intermediador na compra de um medicamento, muitas vezes tirando dúvidas, realizando a troca por genéricos ou similares.

Durante a compra de um medicamento o consumidor passa por um processo de busca, e nesse período recebe influencia de pessoas próximas, como os parentes e amigos. Neste caso, os pacientes recebem a influência dos grupos de referência primário, como cita Kotler e Keller (2006), são esses que influenciam mais 
diretamente sobre o comportamento de compra, principalmente se tratando de um público idoso, em que muitas vezes se encontra sob os cuidados de alguém da família.

A família, como apontada pelo estudo, é uma importante organização consumidor-comprador, para a pessoa idosa a família é considerada o habitat natural, um ponto de auxilio. Assim, podemos considerar que o relacionamento do idoso com a família possui grande influencia em decisões, pois estes grupos de referência mostram ao consumidor novos comportamentos e estilos de vida, afetando, por isso, a decisão de compra.

A propaganda é uma ferramenta do marketing muito valorizada por desempenhar uma variedade de funções. Ela é capaz de informar, persuadir, lembrar, agregar valores e auxiliar a marca. Através da propaganda os consumidores conhecem novos produtos, seus benefícios, o que facilita a criação de imagens positiva diante dos consumidores. Usar a propaganda como uma forma eficiente de comunicação, que alcança um público de massa, facilita o lançamento de novas marcas e aumenta a demanda por outras já existentes. Para Crespo (2005, p.14) "a propaganda eficaz persuade os clientes a testar os produtos e serviços anunciados. A propaganda mantém a marca de uma empresa na memória do consumidor." Pois quando surgir alguma necessidade relacionada ao produto anunciado na propaganda vista pelo consumidor, possibilita que a marca anunciada venha à mente do consumidor no momento da compra. A autora também destaca três formas pelos quais as empresas podem agregar valor às suas ofertas, que seriam a inovação, melhoria de qualidade ou alteração das percepções do consumidor.

Partindo de como o marketing vem sendo utilizado na televisão ao longo do desenvolvimento farmacêutico, passamos a analisar o alto consumo que os idosos fazem da TV (28 entrevistados) e os hábitos desenvolvidos por eles, como o tempo de exposição à TV, programas e gêneros preferidos, etc., nos permite pensar acerca da influência desse meio.

Mesmo com toda a fiscalização atualmente existente, a televisão é um dos principais meios de divulgação de medicamentos de venda livre, e isso ocorre não só nos intervalos comerciais, mas também através de merchandising. Bueno e 
Taitelbaum (2008) destacam uma pesquisa feita em 18.000 farmácias do país, e publicada pelo Jornal do Brasil em julho de 1982, que mostra os medicamentos mais vendidos no país nos anos 80: Novalgina ${ }^{\circledR}$, Anador ${ }^{\circledR}$, AAS, Aspirina ${ }^{\circledR}$, Tylenol $\AA^{\circledR}$ e Melhoral ${ }^{\circledR}$. Desses citados somente Novalgina ${ }^{\circledR}$ era anunciada apenas em revistas especializadas, sendo que os outros ocupavam diariamente os horários nobres da TV, mostrando a forte influencia desse meio de comunicação em cima dos consumidores.

A partir dos anos 40, com o surgimento do rádio como um novo veículo de comunicação de massas, a indústria farmacêutica passou a usar a nova mídia, com uma linguagem publicitária moderna, pois segundo Crespo (2005) os limites de tempo do rádio exigiam uma propaganda mais objetiva, menos rebuscada e literária e bem mais criativa.

O inicio da propaganda no rádio foi regulamentada e autorizada por no governo de Vargas em 1ํ de março de 1932, por meio do Decreto-lei ํㅡ 21.111, como cita Bueno e Taitelbaum (2008). As mensagens publicitárias fizeram com que essa nova mídia passasse a ser popular rapidamente, os programas patrocinados por anunciantes, maior parte deles de medicamentos, viraram uma febre.

Observando os dados apontados neste estudo, a presença do rádio se fez desde muito cedo na vida dessas pessoas (12 entrevistados) que fazem parte do público idoso atual, geralmente desde a infância. O que pode se perceber então é que esse gosto pela escuta do rádio permaneceu. "É um gosto que é certamente composto por uma série de marcas que permaneceram, ao mesmo tempo que negocia com as modificações que se desenvolveram no tempo." 16

Segundo dados do Instituto Brasileiro de Geografia e Estatística (IBGE), cerca de $20 \%$ dos idosos no Brasil tem acesso regular à internet, sendo que esse número está aumentando, dado esse também observado neste trabalho. $O$ uso de redes sociais tem se tornando cada vez mais frequente nesse público, que passa mais tempo conectado, o comportamento é praticamente o mesmo da maioria dos usuários, contato com os amigos, familiares.

A internet apresenta muitas facilidades e vantagens ao idoso, pois de sua residência ele pode se comunicar, ter informações, comprar e realizar pesquisas, por exemplo. A Internet torna-se uma opção de lazer, aprendizagem e inserção social, 
pois vive-se em uma sociedade da informação e este público começa a se interessar pelas novas tecnologias e a utilizá-las em seu favor. Uma pesquisa realizada pelo Comitê Gestor da Internet no Brasil ${ }^{17}$, aponta que entre os consumidores da terceira idade que usam a Internet, sua frequência é de: $47 \%$ diariamente, $29 \%$ pelo menos uma vez por semana, $17 \%$ pelo menos uma vez por mês e $7 \%$ menos de uma vez por mês. É possível observar o quanto é promissor o mercado representado pelo público idoso. Nesse mesmo contexto, onde há um aumento do uso da Internet, espera-se crescimento do uso dela como ferramenta influenciadora nas decisões de compras destes consumidores.

No último gráfico, pode-se observar como a prática de estocagem de remédios é um hábito comum ao público idoso. Isto se explica como consequência ao que foi apresentado neste artigo. A influência do marketing da indústria farmacêutica (em meios como rádio, televisão e internet) além dos profissionais da saúde, ocasiona uma compra exagerada de remédios, mais precisamente de MIPs, que são de fácil acesso. A compra mensal de medicamentos faz com que, inevitavelmente, sobrem medicamentos, e estes permaneçam guardados esperando um uso.

Estocar remédios se tornou comum, e acaba sendo justificada pelos idosos como sobra de tratamento ou simplesmente para prevenção, como remédios para dores de cabeça, estômago ou resfriados. Porém os idosos não se dão conta de que mensalmente repõem seus estoques. Isso ocasiona a automedicação e uso indiscriminado de medicamentos. Automedicação é o uso por conta própria ou por indicação de pessoas não habilitadas, já o uso indiscriminado é relacionado ao consumo excessivo.

Os idosos têm comprado medicamentos que nem sempre são de necessidade de uso. Para Vanzeler e Rodrigues (1999), este hábito de estocar medicamentos muitas vezes acontece por conta do modelo social em que este público encontra-se inserido, onde o consumismo é muito presente.

\section{CONCLUSÃO}

Mesmo com toda a legislação que envolve a propaganda de medicamentos, os MIPs ainda são alvos do marketing usado pela indústria 
farmacêutica, onde um forte público é influenciado, os idosos. Apesar das mudanças ocorridas na forma como o marketing farmacêutico se apresenta, é possível observar ainda um alto uso da mídia televisiva, além do rádio e revistas. Como os idosos atualmente estão inseridos ao uso da internet, esta também passou a ter grande importância para divulgação de MIPs. Porém as estratégias usadas pelas marcas para chegar até esse publico, fiel às farmácias, não param nos meios de comunicação. Profissionais da área da saúde tornaram-se importantes ferramentas para divulgação.

O profissional farmacêutico, por exemplo, com destaque considerável pelos entrevistados, tem forte impacto no comportamento do consumidor diante da compra de medicamentos isentos de prescrição. Tanto o farmacêutico, quanto o balconista da farmácia são influenciados pelo marketing que as empresas utilizam com estes profissionais, em forma de recompensas. Estes, motivados pela vantagem que terão ao vender determinada marca, influenciam na compra de seus clientes. Se tratando de clientes idosos, que frequentemente estão nestes estabelecimentos comerciais, acabam comprando para repor seus estoques, para prevenir uma possível necessidade da medicação ou ainda pela atenção recebia no momento da compra.

A classe mais consumida pelos entrevistados foi a de anti-hipertensivos, que está relacionada com a doenças cardiovasculares propensas ao público alvo deste estudo, sendo que a compra ocorre, no mínimo, uma vez por mês. Compra essa que alimenta a estocagem de medicamentos em casa, pois o público estudado considera que a prática da automedicação é vantajosa pelo fato de se tratar de uma doença crônica e tratamentos semelhantes, ou ainda quando o acesso ao atendimento médico é ineficaz.

As características que determinam a finalização da compra são principalmente o preço, seguido da marca conhecida. $O$ consumidor idoso procura primeiramente preço acessível, mas preza pela qualidade da marca já conhecida. Se tratando de um grupo específico, os idosos procuram a maneira mais simples de administrar o medicamento, sendo assim, também optam pelo modo de administração mais cômodo a eles. 
Sendo assim, este estudo traz dados relevantes à indústria farmacêutica, grande investidora em marketing. Os idosos são hoje os que mais consomem remédios, por isso conhecer suas preferências, os motivos que os levam às farmácias e quais meios possuem maior poder em sua decisão de compra mostram os caminhos que o marketing pode percorrer para chegar a seu público alvo.

\section{REFERÊNCIAS}

1. Das A. Pharmaceutical industry and the market: The case of Prozac and other Antidepressants. Asian Journal of Psychiatry 4. 2011;14-18.

2. Hasenclever L, et al. Economia Industrial de Empresas Farmacêuticas. Rio de Janeiro. E-papers. 2010.

3. Rossi PE. Análise das estratégias competitivas da indústria farmacêutica. [Tese]. [São Paulo]: Universidade de São Paulo; 2001.

4. Hekis $H R$, et al. A indústria farmacêutica e a importância estratégica dos propagandistas de medicamentos: estudo com colaboradores em Natal/RN. Rio Grande do Norte. Revista Holos. 2014.

5. Pereira RA, et al. Marketing Farmaceutico, o Propagandista e o Medicamento Genérico no Composto de Produtos da Indústria Farmacêutica no Rio de Janeiro e São Paulo. [Tese. [São Paulo]: Universidade Estácio de Sá (UNESA); 2000.

6. Rodrigues A, Assmar EML, Jablonski B. Psicologia Social. 27a ed. Rio de Janeiro: Vozes, 2009. $427 \mathrm{p}$.

7. Solomon, MR. O Comportamento do Consumidor. 11a ed. Porto Alegre: Bookman, 2016. 608 p.

8. Richers, R. Marketing: uma visão brasileira. 12a ed. São Paulo: Elsiever Brasil, 2000. $430 \mathrm{p}$.

9. Kiyotani, BP. Análise do comportamento de compra de medicamentos isentos de prescrição e da automedicação. [Tese]. [São Paulo]: Universidade Estadual Paulista (UNESP); 2014. 
10. Custódio B, Vargas SLZ. Propaganda de medicamentos: medicamento e lucro, uma associação pouco saudável. [Tese]. [Rio de Janeiro]: Fundação Oswaldo Cruz; 2005.

11. Kotler P, Kartajaya $\mathrm{H}$, Setiawan I. Marketing 3.0: as forças que estão definindo o novo marketing centrado no ser humano. 1a ed. Rio de Janeiro: Elsevier, 2010. 240 p.

12. Kotler P; Keller KL. Administração de Marketing. 12. ed. São Paulo: Pearson Prentice-Hall, 2006.

13. Sousa CV, Mesquita JMC, Lara JE. Análise da decisão de compra de medicamentos frente à existência de produtos substitutos: um estudo no município de Belo Horizonte, Brasil. Belo Horizonte. Revista Ciência Saúde Coletiva. 2013.

14. Crespo APDCM. As estratégias de marketing no ramo farmacêutico. [Tese]. [Brasília]: Faculdade De Ciências Sociais Aplicadas (FASA); 2005.

15. Bueno E, Taitelbaum P. Vendendo saúde: a história da propaganda de medicamentos no Brasil. 1a ed. São Paulo: Anvisa, 2008.

16. Bianchi G. Midiatização radiofônica nas memórias da recepção: marcas dos processos de escuta e dos sentidos configurados nas trajetórias ade relações dos ouvintes com o rádio. [Tese]. [São Leopoldo]: Universidade do Vale do Rio dos Sinos (UNISINOS); 2010.

17. Comitê Gestor da Internet no Brasil. Pesquisa sobre o uso das tecnologias da informação e da comunicação no Brasil 2005-2009. Ed. especial. São Paulo: Cetic.br, 2010.

18. Vanzeler MLA, Rodrigues MS. Armazenamento de medicamentos em farmácias caseiras em Cuiabá-MT. Rio de Janeiro: Revista Brasileira de Farmácia. 1999. 